\title{
Comparison of Grafts in Post Burn Contractures of Fingers in Children
}

\section{Fatima $\mathbf{M}^{*}$ and Ali Khan FA}

Department of plastic and reconstructive surgery, Dow university of Health sciences, Dr. Ruth K.M Pfau Civil hospital Karachi, Pakistan

*Corresponding author: Dr. Moeez Fatima, Department of plastic and reconstructive surgery, Dow university of Health sciences, Dr. Ruth K.M Pfau Civil hospital Karachi,

\section{Research Article}

Volume 3 Issue 3

Received Date: September 07, 2018

Published Date: October 19, 2018

DOI: $10.23880 /$ cdoaj-16000153 Pakistan, Tel: +92-336-0396173; Email: dr.moeezfatima@outlook.com

\section{Abstract}

Objective: To compare the results of full thickness skin graft (FTG) and split thickness skin graft (STSG), determining which graft is better method of coverage, in terms of range of motion.

Place and duration: Dr. Ruth K.M Pfau Civil hospital Karachi, from January 2012 to march 2018.

Study Design: Cross-sectional study.

Methodology: 180 patients meeting inclusion criteria were enrolled in study, post burn contractures were released and defects were covered with FTG in 100 patients and with STSG in 80 patients. After 2months and physiotherapy, range of motion was compared between two groups.

Results: Mean age at presentation was $4.49 \pm 3.0$ years, mean age at the time of injury was $27.1 \pm 20.7$ months. $55 \%$ patients were males, 45\%were females. Most common mechanism of injury was scald burn $50.6 \%$, followed by contact burn $32.8 \%$, electric burn $11.1 \%$ and flame burn $5.6 \%$. Right hand was injured in $78.3 \%$, left hand in $20 \%$ and both hands in $1.7 \%$ of patients. In patients with FTG, 49\% patients achieved Full ROM, 42\% achieved good ROM, 8\% had Fair and 1\% had poor ROM. In patients with STSG, 22.5\% patients achieved Full ROM, 41.2\% achieved good ROM, 35\% had Fair ROM and $1.2 \%$ had poor ROM.

Conclusion: This study concludes that FTG is a better method of coverage after contracture release.

Keywords: Post burn contractures; Defect coverage; Range of motion

\section{Introduction}

The most common site affected in injuries caused by burn is hand, children being the common victims [1]. Functionality of hand has important role in determining the quality of life [1]. These burns affect daily routine function of hand and affects psychological and social well being of the victim [2]. Burns in children usually occur on volar surface of hand and most frequently occur in children younger than 2 years of age [2]. Early recognition 
of problem, treatment followed by proper splintage and rehabilitation is needed in acute stages, if neglected these victims develop hand deformities of various degrees. Contractures of web spaces and volar surfaces of fingers are a common complication [2]. These contractures result in fibrosis and shortening of soft tissues like skin, tendons, neurovascular bundles, joints and even bones [1]. The most common cause of burns is scald burn, followed by contact with hot object, electric burn (low voltage) [3].

According to McCauley's classification of post burn contracture of hand, there are 4 degrees of contracture [4].

Grade I: Asymptomatic tightening, full ROM, normal architecture.

Grade II: Mild decrease in ROM, no impact on daily activities, no distortion of normal architecture.

Grade III: Functional deficit noticed early changes in normal architecture.

Grade IV: Loss of hand function with significant distortion of architecture.

There are various methods of surgical release of palmer and finger contractures. Methods include multiple z-plasty, release followed by and split thickness skin grafting, full thickness skin grafting, local flaps, regional flaps, island flaps and free flaps [5]. Debate that which skin graft yields better results in terms of functionality of hand and fingers and better aesthetics, still continues.

Many studies have been conducted, some advocate the use of full thickness, [2,6,7] whereas other studies conclude that there is no difference in the outcome of split thickness or full thickness skin grafting used for skin resurfacing provided that adequate physiotherapy is done in post-operative period $[8,9]$.

In this study we have compared the results of Split thickness and full thickness skin graft in cases of post burn contractures of fingers to determine which is the better method of coverage. The outcome was measured in terms of range of motion.

\section{Method}

A) Setting: Department of plastic and reconstructive surgery, Dr. Ruth K.M Pfau Civil hospital Karachi.

B) Duration of study: January 2012 to March 2018

C) Inclusion criteria: Patients who presented in plastic surgery department.

a) Age $\leqslant 12$ years, both genders.

b) Contracture on flexor surface of fingers.

c) After release, tendon or bone was not exposed. d) Post burn contracture of 3rd and 4th degree.

e) ROM: Poor, contracture: >30degree

f) Willing to actively participate in post-operative rehabilitation.

g) Patient without previous congenital or acquired deformities.

D) Exclusion Criteria:

a) Age more than 12 years.

b) Contractures of $1^{\text {st }}$ and $2^{\text {nd }}$ degree, $<30$ degree.

c) Contractures involving dorsum of fingers.

d) Not willing to participate in post-operative rehabilitation and follow-up.

E) Study Design: Retrospective cross-sectional.

\section{Data Collection}

180 patients meeting inclusion criteria were enrolled in this study. In these patients 448 fingers had post burn contractures. In all patients, consent was taken from parents/guardians. Patient's data including age, sex was noted. History including time of injury and mechanism of injury was noted. Hand, fingers involved were documented, degree of contracture was measured by goniometer and noted. Haemoglobin level was checked and x-ray hand was done. Photographs of affected hand were taken as a part of data collection. All contractures were released in a similar manner. Method of resurfacing was decided by operating surgeon at the time of surgery. Patients in whom defect was resurfaced with FTG were included in group A, while STSG resurfaced defects were enrolled in group B. FTG was harvested from groin region, and STSG was harvested from thigh via Humby's knife or silver knife depending upon the size required. Internal splintage was provided in both groups with k-wires. Grafts were checked on 5th post-operative day and take of graft was documented. K-wires were removed after 3weeks of surgery and aggressive physiotherapy was initiated. Patients were called after 3months and ROM was assessed again by goniometer and compared with pre-operative state. Based on post-operative ROM degree, functional outcome was classified as Full, Good, Fair and Poor.

Full: Normal function of hand with full extension of fingers.

Good: Fingers with contracture of $\leqslant 5$ degrees on flexor surface.

Fair: Fingers with contracture of 5-30 degrees on flexor surface.

Poor: Fingers with contracture of $>30$ degree on flexor surface.

Data was analyzed through SPSS version 21. Relevant descriptive statistics, frequency, percentage etc was 
computed for age, sex, mechanism of burn, degree of contracture will each be computed against complications and Chi square test applied. $\mathrm{P}$ value of $<0.05$ was considered significant.

\section{Results}

180 patients meeting inclusion criteria, less than 12 years of age, operated in our institute from January 2012 to may 2018 were enrolled. Mean age at the time of presentation was $4.49 \pm 3.0$ (range 1-12years), mean age at the time of injury was $27.1 \pm 20.7$ (range 3-72months). 99 patients were male (55\%), 81were female (45\%). Most common mechanism of injury was scald burn 91patients (50.6\%), followed by contact with hot object 59(32.8\%), Electric burn 20(11.1\%) and flame burn 10(5.6\%). Right hand was commonly injured $141(78.3 \%)$, in $36(20 \%)$ patients left hand was involved in injury, whereas, only 3 $(1.7 \%)$ patients sustained injury to both hands. Most patients had involvement of more than 1 finger. In total 448 finger contractures were released. Following release, in 100 patients $(55.6 \%)$ defect was covered with FTG, and in 80 patients $(44.4 \%)$ defect was covered with STSG. It was found that different method coverage had significant effect on range of motion, $p$ Value of 0.001. 3 months postoperatively, after physiotherapy, patients were examined and range of motion was assessed. In patients with FTG, 49\% patients achieved Full ROM, 42\% achieved good ROM, $8 \%$ had Fair ROM and $1 \%$ had poor ROM. In patients with STSG, 18 (22.5\%) patients achieved Full ROM, 33(41.2\%) achieved good ROM, 28(35\%) had Fair ROM and $1(1.2 \%)$ had poor ROM.

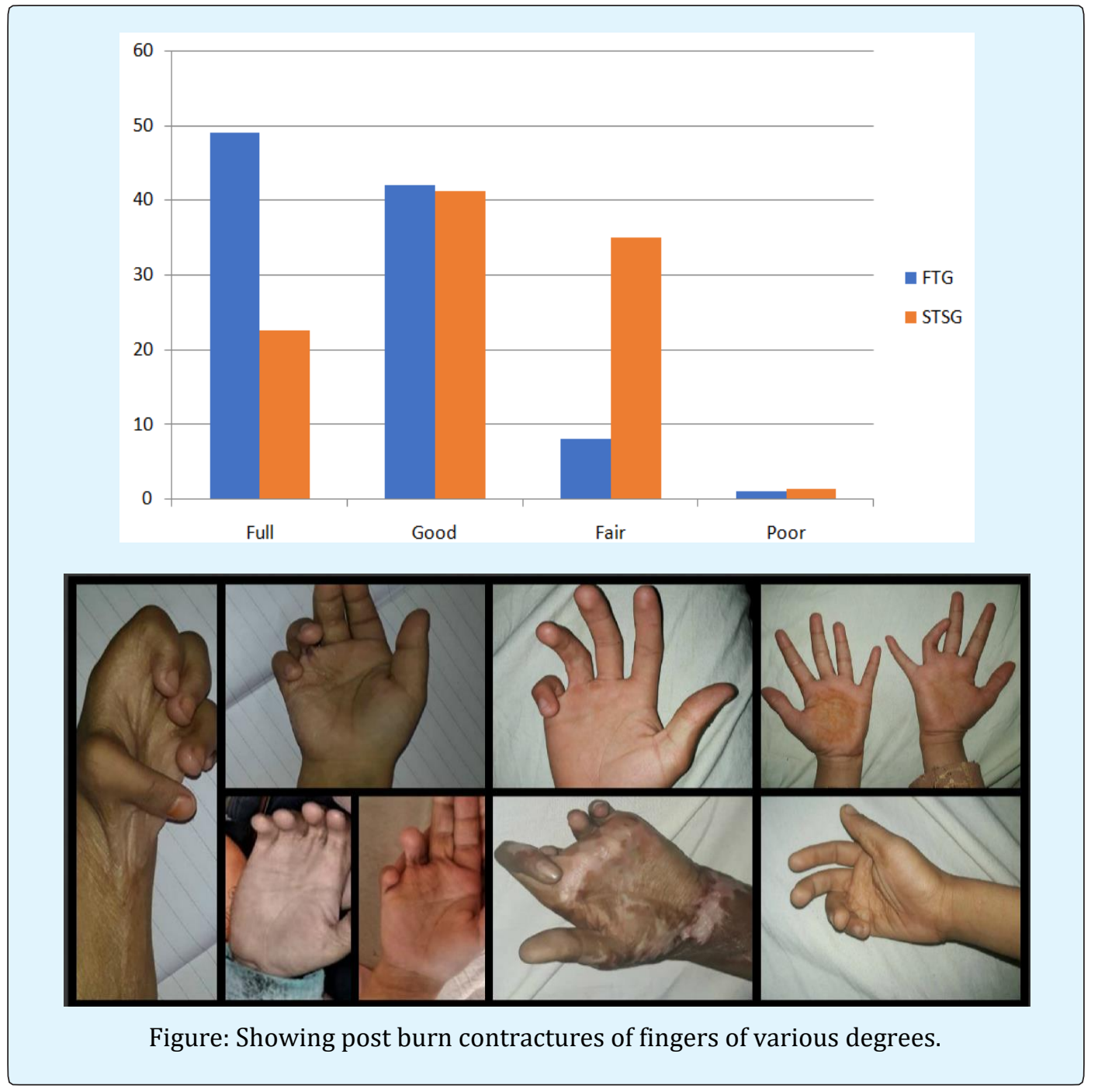

Fatima M and Ali Khan FA. Comparison of Grafts in Post Burn Contractures of Fingers in Children. Clin Dermatol J 2018, 3(3): 000153. 


\section{Discussion}

Hand burns are particularly common in paediatric age group ${ }^{3}$ due to curious and exploring nature and slow reflexes and as a result they sustain injury to hand specially on the volar aspect [10]. Early management of these injuries is essential to restore normal function of hand. Neglecting these injuries and underestimating role of physiotherapy and splinting results in various deformities of hand. In this study we have focused on flexion post burn contractures of fingers. Release of these contractures and coverage of these wounds with which type of graft or flap is debatable. Multiple studies have been conducted with results in favour of FTG $[2,6,7]$, with few studies denying the superiority of FTG over STSG $[8,9]$. FTG has good results in terms of functionality due to more elasticity and less secondary contraction but has limited donor areas [10]. STSG can be used in large defects but has less promising results due to secondary contracture of graft. Range of motion is measured by goniometer to assess function of hand. This ROM can be categorized in full, good, fair and poor.

Results of this study are in favour of full thickness skin grafting as an ideal method of resurfacing defects following release provided that tendon or joint is not exposed. Limitations of study included lack of randomization, small number of patients, individual child's will to do hand exercises to prevent post-operative stiffness and shorter period of follow-up. These limitations can be minimised by prospective study, individualized patient care and randomization [11-14].

\section{Conclusion}

Full thickness skin graft is superior method of resurfacing primary defect following release provided tendons or joints are not exposed. Post-operatively, after removal of K-wire, physiotherapy and night splintage play an important role in determining the outcome.

\section{References}

1. Gupta RK, Jindal N, Kamboj K (2014) Neglected post burns contracture of hand in children: Analysis of contributory socio-cultural factors and the impact of neglect on outcome. J Clin Orthop Trauma 5(4): 215220.

2. Jang YC, Kwon OK, Lee JW, Oh SJ (2001) The optimal management of pediatric steam burn from electric rice-cooker: STSG or FTSG? J Burn Care Rehabil 22(1): $15-20$.

Fatima $\mathrm{M}$ and Ali Khan FA. Comparison of Grafts in Post Burn Contractures of Fingers in Children. Clin Dermatol J 2018, 3(3): 000153.
3. Argirova M, Hadzhiyski O (2005) Treatment of palm burns in children. Ann Burns Fire Disasters. 18(4): 190-193.

4. Bhattacharya S (2013) Avoiding unfavorable results in postburn contracture hand. Indian Journal of Plastic Surgery: Official Publication of the Association of Plastic Surgeons of India 46(2): 434-444.

5. Sunil NP, Ahmed F, Jash PK, Gupta M, Suba S (2015) Study on Surgical Management of Post Burn Hand Deformities. JCDR 9(8): PC06-PC10.

6. Schwanholt C, Greenhalgh DG, Warden GD (1993) A comparison of full-thickness versus split-thickness autografts for the coverage of deep palm burns in the very young pediatric patient. J Burn Care Rehabil 14(1): 29-33.

7. Chandrasegaram MD, Harvey J (2009) Full-thickness vs split-skin grafting in pediatric hand burns--a 10 year review of 174 cases. J Burn Care Res 30(5): 867871.

8. Prasetyono TO, Sadikin PM, Saputra DK (2015) The use of split-thickness versus full-thickness skin graft to resurface volar aspect of pediatric burned hands: A systematic review. Burns 41(5): 890-906.

9. Pensler JM, Steward R, Lewis SR, Herndon DN (1988) Reconstruction of the burned palm: full-thickness versus split-thickness skin grafts--long-term followup. Plast Reconstr Surg 81(1): 46-49.

10. Chan QE, Barzi F, Harvey JG, Holland AJ (2013) Functional and cosmetic outcome of full- versus splitthickness skin grafts in pediatric palmar surface burns: a prospective, independent evaluation. J Burn Care Res 34(2): 232-236.

11. Pham TN, Hanley C, Palmieri T, Greenhalgh DG (2001) Results of early excision and full-thickness grafting of deep palm burns in children. J Burn Care Rehabil 22(1): 54-57.

12. Oh SJ, Kim SG, Cho JK, Sung CM (2014) Palmar crease release and secondary full-thickness skin grafts for contractures in primary full-thickness skin grafts during growth spurts in pediatric palmar hand burns. J Burn Care Res 35(5): e312-e316.

13. Roh TS, Kim YS, Burm JS, Chung CH, Kim JB, et al. (2000) Rice cooker steam hand burn in the pediatric patient. Plast Reconstr Surg 106(1): 76-80. 


\section{Clinical Dermatology Open Access Journal}

14. Bashir MM, Sohail M, Wahab A, Iqbal U, Qayyum R, et al. (2018) Outcomes of post burn flexion contracture release under tourniquet versus tumescent technique in children. Burns 44(3): 678-682.

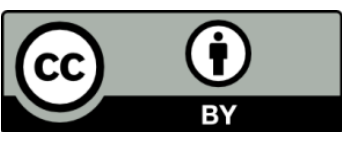

